\title{
Public Policy Orientation Research of Old City Reconstruction YudongHou
}

School of Economics, Wuhan University of Technology, Wuhan 430070, China

Keywords:Old city reconstruction, public policy, public participation.

\begin{abstract}
Urban redevelopment is a very controversial topic in China, meanwhile is also the trendthat social and economic development continue to promote.Three main bodies are concerned in the reconstruction of old city, including local government, the estate developer and local residents. Because of the phenomenon of abusing public benefits, the old city reconstruction policy has encountered legitimacy crisis. To guarantee the compensation and purpose of public benefits, we should take drastic measures to restrain local governments from chasing interest, ensure public it yand transparency during the course of public agenda. Under the concept of affair and impartial rule of law norms, propose correction suggestion of the Government's Role from the establishment of the concept of private property sacred and inviolable, the expansion of citizen participation, improvement of law sander gulation stoexpand citizen participation, and Promotion of market efficiency and supervision.
\end{abstract}

\section{Introduction}

Urbandevelopment of theprocessofongoingurbanexpansionand rebuilding, and it's inseparable with the city's economic development. With the modern industrialization and the development of urbanization, population as sembles to the urban and the size of the cities expands a lot. Since the reform and opening up, the economy of China has been developing rapidly and the level of urbanization has increased a lot, thus many old cities have been unable to meet people's demand of Production and life.

Old city reconstruction refers to the transforming and updating the material life of the old city environment step-by-step, in order to promote the development of the city partially or wholly. [1] Local governments issued the "urban housing demolition management approach", combined with "the Urban Planning Act of the People's Republicof China" and "the Regulation on the Administration ofDemolishment of UrbanHouses", through the way of administrative legislation.

\section{The main bodies of the old city reconstruction}

Generally, in old city reconstruction operation mode, old city reconstructionplan is formulated by the local government's old city reconstruction.Property developers areresponsible for demolition and construction.Reconstruction of old city involvesin 3 main bodies, local government, property developers andlocal residents.

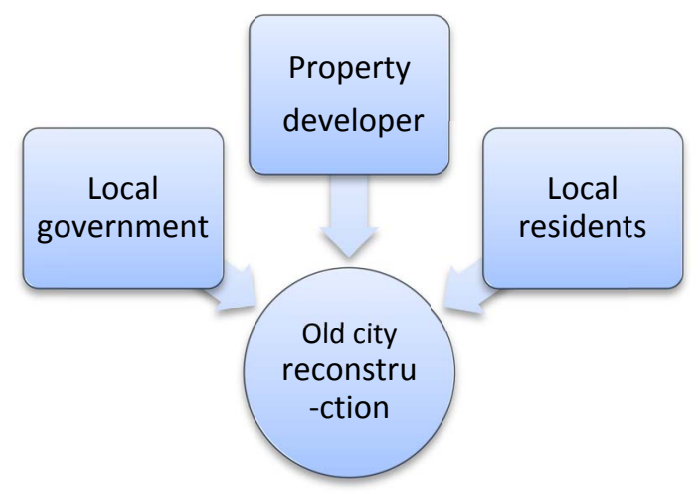

Fig.1 Threemain bodiesinvolvedinold city reconstruction 


\subsection{Local government}

The government represents not only the interests of the public, but also their own interests. [2]In the process of formulation and implementation of urban renewal policy, local government has the responsibility to safeguard regional public interests and their own interest.Through the old city reconstruction, appearance of the city will be improved, urban economic will be developed, residents' life will be more comfortable and convenient.Theseare public interests that the government represents. At the same time, through the old city reconstruction, local government officials have the achievement, which will be helpful for their career promotion. Besides, the local government will get lots of money from charge for the right of land use, which will be useful for the country and for improving working conditions of the government, this is the local governments' own interests.

\subsection{Property developers}

As a pure private organization, the purpose of the propertydeveloper of the old city reconstruction is to obtain maximum economic benefits.At present, developers need to pay fees for compensation, resettlement for the demolition, relocation for the use of the land assets appraisal fees, and marketing management expenses, and so on in the old city reconstruction generally.[3] These costs are the price of developers, but the profit space is still huge.

\subsection{Local residents}

One of the biggest problemsin old city renovation is the housing demolition.At present, there are two ways in the resettlement generally. The one is called monetary indemnity as the market price, namely according to the price of the real estate market to give the local residents monetary compensation; the other one is housing relocation in other place, namely on the basis of is to be demolished housing construction area, the government gives them house property of the same value in other place. However, no matter what kind of compensation and resettlement way is adopted, the total interests of the residents will be damaged in a certain degrees.

\section{Shortcomings of old city reconstructiontheory}

Shortcomings of old city reconstructiontheory is not only the indirect cause of dislocation of rules of urban planning, but also a deterrent to urban planning role transition.Most of Chinese existing urban renewal planning theories arelearned from western developed countries.However, most foreign experience and theory of urban renewal cannot be used on old city reconstruction directly in China.One of the most main reasons is that the urban planning course of developed countries is attached to the pattern of property privatization in the free market economy. Chinese urban planning is planned economy. There isconflict between China and west developed countries. The old city reconstruction of European and American countries put more emphasis on public behavior guidance and control.Westernurban planning plays as the role of "public policy", while Chinese old city reconstruction should strengthen the "top-down" administrative force correction. Chinese old city reconstruction should support the economic marketization, and the inhabitants of the protection of the rights and interests, more to play the role of "public service".

In addition, the old city reconstruction planning process is relatively closed in China. From planning, investigate, and approval to the project implementation, the interests of the residents is not fully considered. Therefore, the fairnessand scientificity of the planning content are questioned. Secondly, as a special planning of urban planning, urban renewal planning lacks a complete system of development and construction. The existing urban overall planning and planning results lack comprehensive study of the problems of urban renewal. 


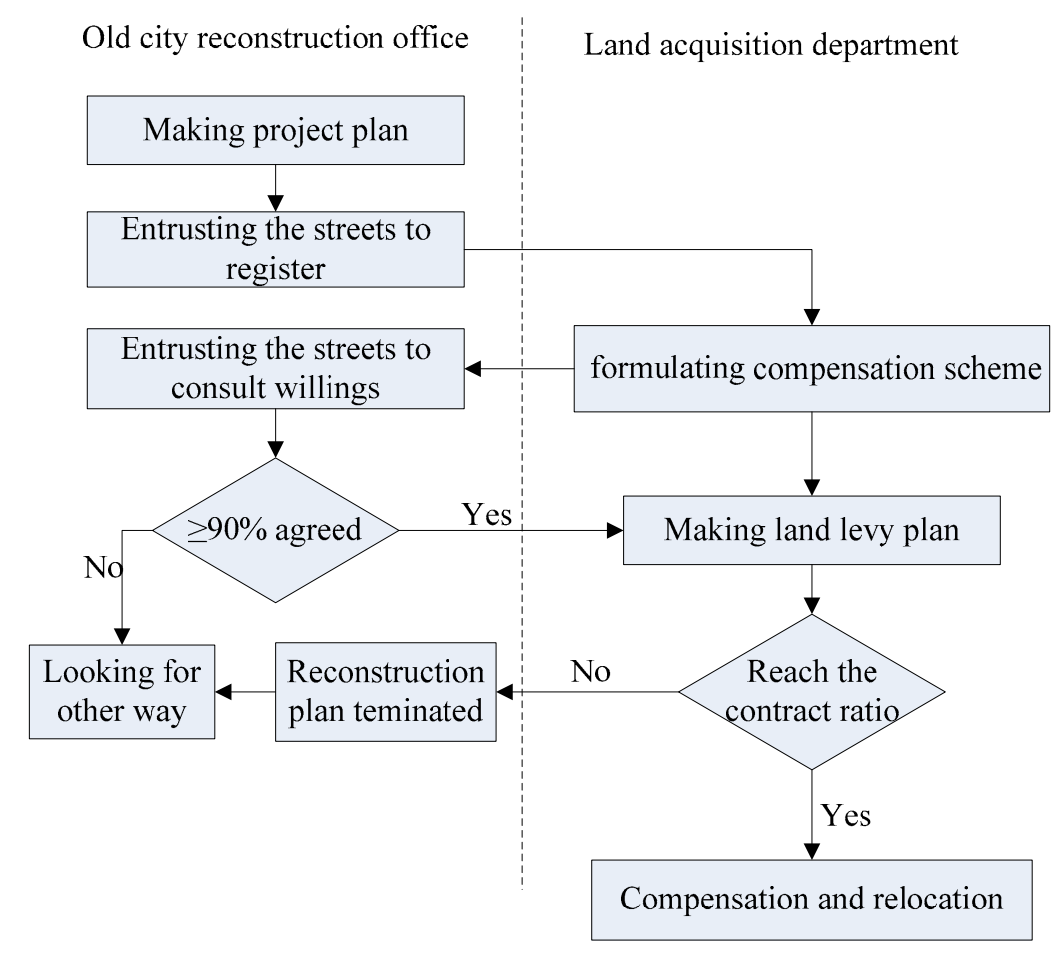

Fig.2demolition and relocation process in some cities

\section{Public policy orientation}

\subsection{Perfect the legal system}

Reducing the legal blank is the most direct route to correctthe role dislocation in executive power. As for the lack of legal norms orlegal contradictions, making relevant rules, clearing rights and obligations of related subject, are necessary.[4] Law should not give a fuzzy description here, defining the right to administrative organs from discretion, but should do more things on the details.For instance, voting proportion of the old city reconstruction should be limited to a certain percent, such as thirty percent. the timing of confirmed the market price should also be clear, because the demolition is a continuous process, time span might be three or four years from application to compensation and resettlement. So many details should be stated clearly.

\subsection{Expandingpublic participation}

The establishment of urban planning is a complicated process. Learning and understanding of planning workers are limited actually. If the public could be participated, such asbrainstorming, the planningwill be more scientific, more conducive for the implement. [5] Public participation can also be watchdog role to the development of economic organization behavior. Due to the negative effects caused by development activity, they should be detected and reported, avoiding the happening of adverse consequences.

\subsection{Perfecting public opinion expression way}

In the process of establishing urban planning, the proposal right is the key. So the open mechanism of issues proposal or compensation mechanism is important meanto protect the interests of vulnerable groups in the old city reconstruction. [6] First of all, through the form of laws and regulations, we should protect the rights of citizens for old city reconstruction planning proposal. The proposal should be investigated seriously. Thorough response mechanism should be established. And feasible proposals should be put enough emphasis.Secondly, we should improve the public right and the ability toput forward feasible and reasonable proposal, which requires the government timely release to the public at the early stage of the planning of city planning. On behalf of the public, participation ability training is necessary to ensure the effectiveness of the public right. 


\section{Summary}

Old city reconstruction improves the urban environment and parts of local residents. However, but the cityappearance change can never build on the expense of the part of the interests of the vulnerable groups. Through the analysis, we found that the local governments and developers obtained the interests from the implementation of urban renewal policy. And generally the interests of property owners will be damaged. The old city reconstruction is a very complex social question. The role of government in the old city reconstruction needs in-depth study based on the multidisciplinary theory. The large-scale urban renewal in China is not only an opportunity, but also a challenge, which needs the joint efforts of the society from all walks of life. They should seize the moment, face the challenge, and adjust measures to local conditions to explore the new mode of old city reconstruction. The economic, social and environmental comprehensive benefit should be maximized to buildbeautiful cities.

\section{References}

[1] Information on http://baike.baidu.com/view/1361738.htm

[2] Jingyu Yang: Analysis of the Role of the Governmentin Reconstruction of the Old City (MS., EastChina Normal Universit, China, 2009), p.18.

[3] Jianwen Huang: Integration and Making of the Public Space inthe Historic Urban Areas Redevelopment(Ph.D., South China University of Technology, China 2011), p.101.

[4] Weilin Feng: Special Zone Economy, (2008) No.4, p.133.

[5] Jian Hu: Modern Business Trade Industry, (2012) No.23, p.47.

[6] Yue Pan, Yuan Liu and Liangping Hong: China Ancient City | Leading Theory of City, (2013) No.9, p.19. 